UK trainees. Outside of London 78\% of respondents had never received any teaching on healthy sleep practices, and $94 \%$ stated they would find this beneficial. Within London $77 \%$ of respondents had received teaching, mostly during ST1 or local induction. $76 \%$ of paediatricians that received training altered either their core sleep practices (11\%), their approach to night shift work (41\%), or both (24\%).

We then surveyed attitudes to the taking of short naps during statutory breaks on night shifts. Because of the LSP's on-going work to raise awareness on this issue, we separate London and non-London responses. Outside of London 36\% of departments actively support naps, 25\% actively discourage them. Within London 48\% of departments support (an increase from 15\% last year) and 10\% discourage (a reduction from 30\%). Unfortunately even where support is in place adequate facilities are lacking in over $50 \%$ of departments.

Conclusions Healthy sleep practices are important, in particular for shift workers. This survey of UK paediatricians demonstrates a lack for training in this area. When teaching is delivered, it results in a change in sleep practices in over $75 \%$ of cases. On-going work by the LSP to raise awareness of these issues has resulted in local departmental changes, however there remains much to improve, both locally and nationally.

\section{P4 ADVERSE EXPERIENCES OF UNACCOMPANIED ASYLUM SEEKING CHILDREN AND THE IMPACT ON THEIR EMOTIONAL WELLBEING AND MENTAL HEALTH NEEDS}

M Emedo, S Habeeb, M Joyce, S Anderson, A Lorek. Community Paediatrics, Guy's and St Thomas'NHS Foundation Trust, London, UK

\subsection{6/archdischild-2018-rcpch.4}

Background All Unaccompanied Asylum Seeking Children (UASC) entering local authority care in England must have a holistic health assessment. Within our local authority this includes history and physical examination using a standardised proforma and Strengths and Difficulties Questionnaire (SDQ).

Methods Retrospective review of records from Jan - August 2016. Recording SDQ scores, experiences of abuse and mental health difficulties.

Results 99 UASC; median age 16 (range 12-17) years, 96\% male. Ten nationalities, mostly Afghani $39 \%$ or Eritrean $35 \%$. High levels of negative life experiences; $46 \%$ had experienced the death of a close family member; $75 \%$ not in contact with any family. In addition to adversity prior to departure, 51\% experienced trauma en route to the UK. 32\% reported detention, 27\% physical assault and 12\% were tortured. Libya was most commonly named, however European countries such as Belgium, Hungary and Bulgaria were also identified as locations of abuse. SDQ scores outside the normal range for emotional distress in 37\%, peer relationships in $17 \%$ and overall stress in $13 \%$. There was a statistically significant association (Fisher's exact test; $\mathrm{p}=0.0003$ ) between high SDQ score for emotional distress and adverse experiences during transit to the UK. $43(43 \%)$ were identified as needing referral to mental health services.

Discussion Data from our cohort demonstrates a high burden of distress, with large numbers of UASC experiencing abuse in transit to the UK. This is significantly associated with high levels of emotional distress in our cohort. The predictable need in this population should be accounted for in planning for and increasing access to mental health services.

\section{P5 HORIZONTAL SCHOOLS-BASED HEALTH PROGRAMME IN RURAL KENYA: HEALTHSTART}

1J Bogie, 'B Eder, ${ }^{2} \mathrm{D}$ Amonje, ${ }^{3} \mathrm{M}$ Gant, ${ }^{1} \mathrm{D}$ Magnus. ${ }^{1}$ Faculty of Medicine and Dentistry, University of Bristol, Bristol, UK; ${ }^{2}$ Monitoring and Evaluation, OGRA Foundation, Kisumu, Kenya; ${ }^{3}$ International Programmes, Child.org, Nairobi, Kenya

10.1136/archdischild-2018-rcpch.5

Background Children in low-income countries are at increased risk of poor health, which can affect attendance, cognition and ability to learn. Developing school health and nutrition strategies has been extensively highlighted as a global priority, with a particular focus on complex programme design and use of the FRESH framework. However, such programmes are relatively untested in low-income settings, despite that they may improve academic attendance and achievement.

Method We implemented a complex school health and nutrition programme in two schools in Western Kenya over 3 years, with a programme evaluation following the intervention. There were numerous outputs covering health policy, skillsbased health education, infrastructure and disease prevention. A local non- governmental organisation, with involvement from local government and the community, performed programme implementation. Height-for-age, weight-for-age, heightfor-weight, anaemia prevalence, academic performance and school attendance were the primary outcome measures.

Results The programme improved nutrition, academic performance and anaemia prevalence. The number of underweight children fell from $20 \%$ to $11 \%$ (OR $0.5195 \%$ CI 0.39 to $0.68 \mathrm{p} \leq 0.01)$ and stunting prevalence fell from $29.9 \%$ to $20 \%$ (OR $0.5995 \%$ CI 0.50 to $0.68 \mathrm{p} \leq 0.01$ ). Academic performance improved with a $74 \%$ reduction in odds of failing assessments (OR $0.26 \quad 95 \%$ CI 0.22 to $0.29 \mathrm{p} \leq 0.01$ ). Anaemia prevalence fell from $17.2 \%$ to $11 \%$. The programme showed an increase in low body mass index prevalence and no effect on school attendance, the reasons for which are unclear.

Discussion These results are encouraging and demonstrate that complex schools health programmes can lead to positive gains in health, nutrition and importantly academic performance. However they are not conclusive and there is a need for further evaluation of comprehensive school health interventions in poor communities.

\section{P6 DO CHILDREN REALLY DIE FROM 'FLU? NATIONAL SURVEILLANCE FOR INFLUENZA RELATED SEVERE COMPLICATIONS IN AUSTRALIAN CHILDREN}

\begin{abstract}
${ }^{1,2}$ YA Zurynski, ${ }^{1,2} \mathrm{M}$ Deverell, ${ }^{1,2} \mathrm{~A}$ Phu, ${ }^{1,3,4} \mathrm{R}$ Booy, ${ }^{1,2,4} \mathrm{EJ}$ Elliott. ${ }^{1}$ Discipline of Child and Adolescent Health, The University of Sydney, Sydney, Australia; ${ }^{2}$ Australian Paediatric Surveillance Unit, Kids Research Institute, Sydney, Australia; ${ }^{3}$ National Centre for Immunisation Research and Surveillance, Kids Research Institute, Sydney, Australia; ${ }^{4}$ Clinical School, The Sydney Children's Hospitals Network, Children's Hospital at Westmead, Sydney, Australia
\end{abstract}

\subsection{6/archdischild-2018-rcpch.6}

Aims Severe complications and deaths due to influenza in children were reported during the 2009 influenza pandemic, but there are few reports for non-pandemic periods. We aimed to address this gap in knowledge by describing severe outcomes of influenza among Australian children from 2008 to 2016. Methods We conducted surveillance through the Australian Paediatric Surveillance Unit (APSU) during July to September 